\title{
A RETÓRICA EPIDÍTICA E 0 CONJUNTO ESCULTÓRICO DO POÇO DE MOISÉS
}

\author{
Paloma Lima Santos Mariano \\ Mestra em Estudos Literários, \\ Universidade Federal do Espírito Santo
}

\begin{abstract}
Resumo
O objetivo deste trabalho é analisar a presença de estratégias da retórica epidítica associadas à obra de Claus Sluter no conjunto escultórico do Poço de Moisés, na antiga Cartuxa de Champmol, em Dijon, datado de c. 1400. Buscaremos demonstrar que se trata do trabalho de um artista retórico que não abdica do ornamento, do adorno, da disciplina da arte como discurso.
\end{abstract}

\section{Pallavras-chave}

Claus Sluter • Poço de Moisés • retórica epidítica.

\section{Contato:}

Rua Peixoto Gomide, 462/20A

São Paulo - SP - 01409-000

E-mail:paloma_1s@yahoo.com.br

* Todas as imagens mencionadas neste artigo estão reproduzidas no Caderno de imagens. 


\title{
EPIDEICTIC RHETORIC AND SCULPTURAL COMPLEX OF THE \\ WELL OF MOSES
}

\author{
Paloma Lima Santos Mariano \\ Master in Literary Studies, \\ Universidade Federal do Espírito Santo
}

\begin{abstract}
The purpose of this article is to analyze the use of strategies originating in the genre of epideictic rhetoric in Claus Sluter's Well of Moses in the Charterhouse of Champmol, in Dijon, dated around 1400. It will be argued that the Well is the work of an artist that makes ample use of rhetorical strategies, resorting to ornament and adornment, using art as a form of discourse.
\end{abstract}

Keywords

Claus Sluter $\bullet$ Well of Moses $\bullet$ epideictic rhetoric.

\section{Contact:}

Rua Peixoto Gomide, 462/20A

São Paulo - SP - 01409-000

E-mail:paloma_1s@yahoo.com.br 


\section{Introdução: 0 eclipse da retórica}

Neste trabalho, pretendemos investigar a presença de estratégias da retórica epidítica e da ideia de "desvio" na obra de Claus Sluter (c. 1340/1350-1415/16) no conjunto escultórico do Poço de Moisés. ${ }^{2}$

Ainda hoje há quem acredite que a abordagem retórica esteja ligada somente aos artifícios ardilosos de persuasão. Muito dessa percepção da retórica devese ao fato de que esta sofreu um processo de exclusão cujas razões históricas, apontadas por Bender e Welberry em seu estudo sobre o retorno modernista da retórica, ${ }^{3}$ parecem-nos importante objeto de reflexão.

É, sobretudo, durante o Iluminismo e o Romantismo que "elementos a-retóricos" preponderam, respectivamente buscando sua exclusão no domínio teórico e prático e no domínio estético. Uma das principais marcas do Iluminismo, no que diz respeito às características discursivas, é a busca de uma forma de discurso neutra, livre de posicionamentos individuais:

Em parte alguma essa tendência fica mais visível que no surgimento da ciência, a mais poderosa inovação do mundo pós-renascentista. (...) Desde o início, a ciência se firmava na convenção de uma descrição supostamente verdadeira e não distorcida - isto é, a-retórica, de estados de coisas naturais. ${ }^{4}$

Trata-se, portanto, de um momento cujos valores contradizem os da retórica clássica, em que o texto está amplamente relacionado a características únicas do orador e de sua plateia e em que fatores tais como idade, status e educação são fundamentais para a confecção da trama discursiva.

Além disso, trata-se de um tempo histórico em que se defendia a existência da verdade, de uma única verdade como resposta natural para as perguntas e problemas. Com base nisso, firmavam-se as ciências, contra a ilusão e a ambiguidade, características, segundo Platão, da arte da retórica empregada pelos sofistas.

O Novum Organum de Bacon concentrou e sistematizou esse conflito ao mesmo tempo em que lançou as bases do pensamento científico moderno ao condenar

1 REBOUL, Olivier. Introdução à retórica. Trad. Ivone Castilho Benedetti. São Paulo: Martins Fontes, 2004, p. 65.

2 Um colóquio, organizado em Dijon entre 16 e 18 de outubro de 2008, trouxe recentemente à baila esse importante conjunto escultórico. Para um resumo dos principais argumentos avançados no colóquio, cf. JUGIE, Sophie e RUSSO, Daniel. Autour du Puits de Moïse: Pour une nouvelle approche. Bulletin du Centre d'Études Médiévales d'Auxerre, v. 13, 2009, p. 237-242. Igualmente acessível on-line no endereço seguinte: http://cem.revues.org/index11075.html

3 WELLBERY, David E.; BENDER, John. Retoricidade: Sobre o retorno modernista da retórica. In: WELLBERY, David E. Neo-retórica e desconstrução. Trad. Angela Melim e Johannes Kretschmer. Rio de Janeiro: EdUERJ, 1998, p. 11-47, p. 13-28.

4 Id., ibid., p. 15. 
de diversas maneiras o pensamento retórico. Bender e Welberry evidenciam, em particular, a crítica de Bacon aos idoli fori, ${ }^{5}$ espelho do embate entre Platão e os sofistas. Não se desejava mais, portanto, um discurso como o da retórica clássica, nascido das relações sociais e da dinâmica dos poderes hierarquicamente manifestados, mas um discurso que se originasse do domínio do homem sobre a natureza através do conhecimento. Não mais o homem persuasivo, mas o sujeito abstrato. Descartes, por sua vez considerado o fundador da filosofia moderna, rejeitava o ensino da retórica e sua prática e defendia que o gênio se exprimiria de modo suave, claro e inteligível mesmo que nunca tivesse sido preparado ou instruído para tanto. Assim como na teoria poética romântica, o talento seria inerente à própria existência do gênio; sua arte habitaria seu interior.

Bender e Welberry sintetizam assim a afinidade entre Iluminismo e Romantismo no intuito compartilhado de destruir a retórica:

O cogito, o fundamento inquebrantável da certeza, gera ao mesmo tempo o sujeito impessoal ou abstrato da ciência e o sujeito criativo, autoformador do Romantismo. Uma vez que essas funções subjetivas tomaram o comando do campo do discurso e da representação, a retórica não pode mais manter sua predominância cultural. A subjetividade fundadora, ou seja, o sujeito como res cogitans ou como origem criativa, como personalidade individual única ou como agente livre desinteressado no interior da esfera política - erode as premissas ideológicas da retórica. ${ }^{6}$

Da constelação de fatores a serem considerados, os autores destacam ainda outros três que consideram proeminentes para a decadência da retórica, quais sejam: o surgimento do discurso político liberal como linguagem da troca comunitária, o surgimento da imprensa e da publicação e o surgimento das línguas nacionais padronizadas como referência cultural para produção e compreensão. ${ }^{7}$

$\mathrm{O}$ estudo da retórica que aqui nos interessa preponderantemente foi, assim, relegado a um plano inferior até seu esquecimento quase total. Ausente durante muito tempo do sistema hegemônico de comunicação e, por conseguinte, da crítica artística e literária, a ideia de retórica passou a ser sinônimo de discurso supérfluo, associada ao paramento luxuoso ou de mau gosto.

A importância de refletir sobre o Poço de Moisés a partir de uma perspectiva retórica saltou-nos aos olhos a partir de dois elementos: a própria constituição

\footnotetext{
Por meio da crítica aos ídolos de mercado, Bacon elabora uma denúncia das ilusões de um discurso que se amolda aos desejos e apelos populares. Id., ibid, p. 15.

6 WELLBERY, David E.; BENDER, John. Retoricidade, art. cit., p. 19.

7 Id., ibid., p. 14-15.
} 
do conjunto escultórico e a leitura de algumas descrições deste conjunto, especialmente a de Johan Huizinga, no clássico O outono da Idade Média ${ }^{8}$ Embora reconheça o mérito dos artistas envolvidos na execução da obra, o autor pontua certos elementos como "excessos", ou como aparatos desnecessários. ${ }^{9}$ As lunetas feitas especialmente para o Jeremias, um dos profetas do conjunto, são consideradas elementos do bizarro, ${ }^{10}$ o que aponta para a percepção de que elementos retóricos constituir-se-iam como aparatos supérfluos e de mau gosto.

Outros estudos mais contemporâneos sobre a obra de Sluter, como o de John Moffit, de 2005, embora não tratem mais certos elementos de modo pejorativo, ainda se valem em suas análises de certa ideia de dramaticidade que sugere um exagero realista, assim como renunciam à análise específica dos procedimentos do artista, contentando-se com o uso de termos abstratos para descrever a obra, tais como "força", "inspiração" e "intensidade", como no exemplo a seguir:

These six figures, with each one both physically and physionomically differentiated, were treated with exceptional force. Their individually dramatized poses, with boldly handled curves and broken edges in the draperies, reflect the intensity of Sluter's inspiration which, as many observers have remarked, precociously anticipates Michelangelo's terribilita, specially when the Italian master's famed Moses (Rome, S. Pietro in Vincoli) is compared to the boldly modeled, psychologically acute Moise of his lesser-known Netherlandish predecessor in Dijon. ${ }^{11}$

O que pretendo brevemente mostrar é que, nesse conjunto, nenhum elemento é supérfluo, mas que todos eles se articulam retoricamente criando um conjunto especialmente interessante do ponto de vista de sua organização, disposição e das escolhas feitas pelos artistas. Pretendo fazê-lo demonstrando que, às palavras abstratas comumente utilizadas para descrever a obra de Sluter, é importante somar-se um olhar minucioso sobre os procedimentos retóricos do artista, os quais intento aqui brevemente exemplificar.

8 HUIZINGA, Johan. O outono da Idade Média. Trad. Francis Petra Janssen. São Paulo: Cosac \& Naify, 2010.

9 Id., p. 443.

${ }^{10}$ Id., p. 444.

${ }^{11}$ MOFFIT, John. Sluter's "Pleurants" and Timanthes" "Tristitia Velata": Evolution of, and sources for a humanist topos of mourning. Artibus et Historiae, v. 26, n. 51, 2005, p. 74. 


\section{O conjunto escultórico do Poço de Moisés: retoricidade e o papel da palavra}

Dito isso, passemos então à apresentação do conjunto.

Originalmente, a obra era um grande calvário no centro de uma fonte, com uma cruz de seis metros de altura [fig. 1, pág. 269]. Ela foi edificada por volta de 1400, por encomenda do primeiro duque da Borgonha, da casa de Valois, Philippe, o Bravo (1342-1404), no centro do claustro da cartuxa de Champmol, por ele fundado às portas da cidade de Dijon.

De acordo com John Moffit, mesmo antes da Revolução Francesa, provavelmente em 1792, a parte superior do conjunto, com o Cristo crucificado, a Virgem, São João e Maria Madalena, já havia sido destruída por revolucionários iconoclastas. ${ }^{12}$ Atualmente, no local, resta do conjunto apenas a sua base, conhecida como o Poço de Moisés [fig. 2, pág. 270]. Ela é composta por uma pilastra ornamentada com seis personagens bíblicos (Moisés, Davi, Jeremias, Zacarias, Daniel e Isaías) e seis anjos. O busto do Cristo crucificado, peça remanescente do conjunto original, atualmente se encontra no Museu Arqueológico de Dijon.

Os personagens que compõem o pedestal são os seis profetas que predisseram a morte do Cristo no Velho Testamento e uma cornija formada por anjos carpideiros (pleurants).

Os profetas trazem rolos que contêm o texto, em latim, de suas respectivas predições.

O texto apresentado por Moisés diz: "Immolabit agnum multitudo filiorum Israhel ad vesperam" (À noite a multidão de filhos de Israel imolará o cordeiro) (Êxodo 12, 6 e Levítico 14, 13).

Davi traz consigo um trecho do salmo 22, "Foderunt manus meas et pedes meos, numerarunt ossa" ("Traspassaram-me as mãos e os pés, contaram os meus ossos") (Salmos 22, 17-18).

O texto que traz Jeremias, extraído do Livro das Lamentações, diz: "O vos omnes qui transitis per viam, attendite et videte si est dolor sicut dolor meus" ("Não vos comove isto a vós, homens que passais pelo caminho? Atendei, e vede, se há dor como a minha dor") (Jeremias 1, 12).

Zacarias, profeta que anunciou a traição de Judas, traz consigo o seguinte texto "Appenderunt mercedem meam triginta argenteos" ("Eles estimaram o meu resgate em trinta moedas de prata") (Zacarias 11, 12).

${ }^{12}$ Id., p. 74. 
Daniel, por sua vez, apresenta um oráculo: "Post hebdomadas sexaginta duas occidetur Christus" ("Depois de sessenta e duas semanas, o Cristo será morto") (Daniel 9, 26).

Isaías traz a seguinte profecia: "Sicut ovis ad occisionem ducetur, et quasi agnus coram tondente se obmutescet et non aperiet os suum" ("Ele será conduzido à morte como uma ovelha, e como um carneiro frente ao tosador, ele se calará e não abrirá a boca”) (Isaías 53, 7).

O Poço de Moisés é um conjunto escultórico de caráter fortemente narrativo, uma obra que diz respeito ao verbo, palavra, tanto quanto ao Verbo, Cristo. A própria escolha dos profetas como base sustentatória do calvário remete à importância do discurso. A palavra sustenta a cena. É em função do que disseram que os profetas ali se encontram, a transformação de sua previsão em palavras é parte do milagre que antecipou a chegada do Cristo.

Para refletir sobre a natureza narrativa desse conjunto escultórico, portanto, quando optamos por uma reflexão de viés retórico, não nos referimos à retórica clássica, cuja tradição situou o discurso em uma malha de limitações, um domínio governado por regras cujos procedimentos eram próprios das instituições que organizavam a interação europeia tradicional, mas, com David Welberry, pensamos em termos de retoricidade, ou seja, pensamos a retórica "não mais como título de uma doutrina e uma prática, nem forma de memória cultural", ${ }^{13}$ mas, em vez disso, como uma condição de realização de todo metadiscurso.

Quando professor de letras clássicas da Universidade de Basiléia, Nietzsche deu um curso de retórica e seu texto inicial, "Sobre verdade e mentira no sentido extramoral", ${ }^{14}$ insiste especialmente na retoricidade essencial da linguagem, de toda e qualquer linguagem, e trata as metáforas "como um impulso humano", base essencial de nossa explicação do mundo.

Assim, com Nietszche, o conceito de figuras de discurso herdado da retórica clássica sofre uma reinterpretação: as figuras não são mais dispositivos de uma elocutio que adorna e apresenta os pensamentos inventados pelo orador, mas categorias móveis que estão sempre em funcionamento em cada encontro com o mundo. Nesse mesmo momento de sua carreira, Nietzsche desenvolveu a noção de que a própria verdade é produto de um determinado pathos, uma figura investida de afetividade, que não é capaz de reivindicar legitimidade além da própria urgência com que é afirmada. Esse movimento conceitual rompe os

\footnotetext{
${ }^{13}$ WELLBERY, David E.; BENDER, John. Retoricidade, art. cit., p. 32.

${ }^{14}$ NIETZSCHE, Friedrich. Sobre verdade e mentira no sentido extramoral. In: Idem. Obras incompletas. São Paulo: Abril, 1974 (Col. Os Pensadores, vol. 31).
} 
fundamentos da noção da existência de uma linguagem a-retórica ou mesmo de uma observação a-retórica, ou seja, inclusive as afirmações de verdade das ciências são uma retórica, entre tantas.

Para o filósofo, portanto, a aparência não é o oposto de verdade, mas inclui a verdade como uma de suas variantes. Logo, se toda linguagem é retórica, e mesmo a objetividade é produto de certa estratégia, então os discursos não devem ser medidos em relação a sua adequação ou desvio de um padrão objetivo (que, para Nietzsche, é um mito), mas, em vez disso, os discursos devem ser analisados em termos de suas opções estratégicas dentro de uma determinada circunstância, já que "as forças concorrentes dentro de um conflito constituem-se elas próprias nas e através das dissimulações retóricas que empregam". ${ }^{15}$

A retórica, portanto, aparece, em Nietzsche, nem só como doutrina que governa a produção e a análise de textos, nem apenas como procedimento a ser empregado com determinados fins, mas como um fim em si mesmo, um a priori que o pensamento não terá jamais sob total controle porque o próprio pensamento é produto desse processo. O conceito de retoricidade, cunhado por Bender e Welberry, evidencia a universalidade da condição da retórica, destaca sua não restrição a condições específicas de comunicação formal e situa as figuras de linguagem, como afirmam Dan Sperber e Deirdre Wilson, como simplesmente explorações criativas de uma dimensão geral de uso da linguagem, ${ }^{16}$ que não se aplicam apenas ao texto tal como concebido pela retórica clássica, mas observáveis em um conjunto ilimitado de opções de elocução e que constituem, portanto, a própria essência de toda transação comunicativa.

Assim, cremos, as inscrições presentes no conjunto escultórico do Poço de Moisés chamam atenção para o caráter narrativo da obra, ao mesmo tempo que são avatares de sua constituição retórica. Sobretudo porque não se trata de textos quaisquer, mas de palavras investidas de uma força simbólica rara: a das palavras proféticas. Moisés, por exemplo, tem o rolo que está em torno de seu corpo quase como se as palavras o vestissem [fig. 3, pág. 271], mas traz também em sua mão direita a tábua com os mandamentos, voltada não para seus olhos, mas exibida ao espectador. É um personagem legitimado por ter recebido a palavra, a lei escrita por Deus. Ele mostra em suas mãos as palavras que recebeu e, simultaneamente, exibe aquelas que entregou ao mundo. Não sem razão e provavelmente por essa

${ }^{15}$ NIETZSCHE, F. Da Retórica. Lisboa: Vega, 1995, p. 59.

${ }^{16}$ SPERBER, Dan; WILSON, Deirdre. Rhetoric and relevance. In: WELLBERY, David; BENDER, John (ed.). The ends of rhetoric: History, theory, practice. Stanford: Stanford University Press, 1990, p. 140-155. 
dupla função retórica do personagem, a obra que era originalmente uma fonte, fonte da vida, ficou conhecida como o Poço de Moisés.

\section{O Poço de Moisés e o gênero epidítico: elogio do Cristo, do comitente e do artista}

O lugar que as palavras ocupam, nas mãos dos profetas na base do calvário, dá-nos indícios de sua importância e de sua intenção retórica. Segundo os antigos, os gêneros oratórios são três: judiciário, deliberativo (ou político) e epidítico (ou demonstrativo). Aristóteles explica que esses gêneros existem em função dos três tipos de auditório. ${ }^{17}$ A necessidade de adaptar-se a eles confere traços específicos a cada gênero. Conforme a pessoa a quem se dirige, o discurso será, portanto, diferente. Para a Assembleia, o discurso deliberativo; para o tribunal, o judiciário; para todos os espectadores que assistem a discursos de aparato, como panegíricos, orações fúnebres e outras, o epidítico. Para Aristóteles, os discursos distinguem-se também pelo tempo. O judiciário refere-se ao passado, pois são fatos passados que cumpre esclarecer, qualificar e julgar. O deliberativo refere-se, sobretudo, ao futuro, pois inspira decisões e projetos. Já o epidítico refere-se ao presente, pois o orador propõe-se à admiração dos espectadores ainda que para isso extraia argumentos do passado.

O discurso que cerca o conjunto escultórico nos parece estar, em diversos aspectos, ligado ao gênero epidítico ou demonstrativo que, para Heinrich Lausberg, "possui as funções de louvor e de censura e tem como caso paradigmático o discurso festivo, em honra de uma pessoa que deve ser celebrada (e, portanto, louvada), pronunciado por um orador para isto mesmo contratado". ${ }^{18}$ Esse gênero também inclui o elogio feito ao morto, quando, segundo Olivier Reboul "parte-se daquilo que todos conhecem, para exaltar seus méritos e calar o resto". ${ }^{19}$ Os fatos relativos à situação discursiva, pressupõe-se, são conhecidos do público e cumpre ao orador dar-lhes valor, mostrando sua importância e sua nobreza. ${ }^{20}$

O Poço de Moisés conjuga, pelo menos, três discursos epidíticos ou louvatórios, três elogios, o do Cristo morto, o do duque que encomendou a obra e o do mérito do próprio artista.

\footnotetext{
${ }^{17}$ ARISTÓTELES. Retórica, 1358a. In: Idem. Obras completas, v. 8, t. 1. Trad. Manuel Alexandre Jr.; Paulo Farmhouse Alberto; Abel do Nascimento Pena. Lisboa: Imprensa Nacional/Casa da Moeda, 2005, p. 104.

${ }^{18}$ LAUSBERG, Heinrich. Elementos de retórica literária. Trad. R. M. Rosado Fernandes. Lisboa: Calouste Gulbenkian, 2004, p. 84.

${ }^{19}$ REBOUL, Olivier. Introdução à retórica, op. cit., p. 46.

${ }^{20}$ ARISTÓTELES, Retórica, 1368a, op. cit., p. 129-130.
} 
O primeiro e mais explícito é o elogio ao Cristo, elogio fúnebre a um morto cujos fatos da vida eram grandemente conhecidos dos principais espectadores a quem a obra era destinada, já que a encomenda do duque de Borgonha ocupava o centro do claustro do mosteiro cartuxo de Champmol. O busto nos dá uma ideia do realismo e do pathos da escultura do Cristo crucificado tal como foi pensada e executada. Todos os outros personagens e seus discursos e, logo, a obra como um todo, erguem-se como uma lamentação da morte do Cristo.

De acordo com Lausberg, ${ }^{21}$ a dispositio - a escolha e ordenação das partes que fazem a totalidade de uma obra - obedece (exceto nos casos de uma ruptura por medidas violentas) a uma certa sequência fixa de procedimentos. $\mathrm{Na}$ língua, por exemplo, a ordenação gramatical das palavras dentro de uma frase é socialmente convencionada, e na arte há também uma tradição iconográfica para a representação de determinadas cenas, sobretudo as que fazem referência às Escrituras. Ao mesmo tempo, porém, no domínio da estruturação do pensamento e da lógica interna de cada obra, o artista pode dispor de certa liberdade. A obra, então, surge do conflito entre a liberdade do artista e a coerção mais ou menos forte das normas, sejam elas sociais, estabelecidas pelo comitente, normas teológicas, dentre outras.

Ensina-nos Cícero que a bipartição de uma totalidade acentua a sua tensão. ${ }^{22}$ $\mathrm{O}$ discurso pode possuir duas partes em oposição uma à outra e ambas contidas no todo. O caso paradigmático da bipartição seria, portanto, a antítese. Mas o discurso pode também ser tripartite. Neste caso, as principais partes são caput, medium e finis, princípio, meio e fim. Cada uma dessas partes pode ser subdividida, gerando discursos com quadripartições, quinquepartições e assim por diante.

O princípio e o fim do discurso podem estar em oposição, enquanto o meio dedica-se à matéria propriamente dita. No entanto, o drama, segundo Lausberg, mostra uma bipartição em que o enlaçar do nó ou a chave do enredo ou do tema opõe-se à catástrofe. ${ }^{23}$ No caso do Poço de Moisés, em seu discurso figurativo, o enlace, ou seja, segundo Lausberg, a "fase preparatória ou de informação" que

${ }^{21}$ LAUSBERG, Heinrich. Elementos de retórica literária, op. cit., p. 49-63.

${ }^{22}$ Ao tratar dos discursos pertencentes ao gênero a que os gregos chamavam epideiktikón, Cícero nos explica que assim eram conhecidos tais discursos porque compostos para o puro deleite e como que para uma demonstração de bravura (Quase ad inspiciendum delectaciones causa). Para ele, no entanto, o elogio da simplicidade que distingue o epideiktikón do estilo ático não implica que o orador deva renunciar a ornar o seu discurso com algumas das "flores" de que se servem os sofistas, mas apenas que os sofistas servem-se delas mais abertamente porque visam tanto a seduzir quanto a persuadir. CÍCERO. Orator, 37. Texto latino disponível em: http://www. thelatinlibrary.com/cicero/orator.shtml\#37.

${ }^{23}$ LAUSBERG, Heinrich. Elementos de retórica literária, op. cit., p. 98. 
prepara a situação (protasis) parece-nos representada pelos personagens centrais da base hexagonal, os profetas. Eles cumprem o exato papel de introdução ao tema, tanto no sentido bíblico, como anunciadores do sacrifício do Cristo, como no sentido da disposição da obra: na altura do olhar do espectador, em tamanho natural e trazendo consigo o texto de suas profecias, eles preparam o espectador para a cena posterior a eles, cena que eles sustentam, anunciado-a.

A epitasis, ainda segundo Lausberg, a parte que contém o enredo principal do drama, pode ser subdividida "em uma epitasis dinâmica e numa catastasis estática". ${ }^{24} \mathrm{O}$ que significa que, além do centro do drama, do clímax do desenvolvimento de seu tema, pode haver um momento retardante, que antecede e apresenta o resultado da situação. A crucifixão antecede a morte do Cristo, mas, na representação do calvário, causa e consequência estão aderidas a uma única imagem, metonimicamente. A imagem do Cristo na cruz condensa tanto seu sofrimento como sua morte - é epitasis e catastasis.

Nesse sentido, as figuras dos anjos carpideiros, os pleurants, são particularmente interessantes [fig. 4, p. 272]. Eles também contêm em si o duplo: choram a morte do Cristo e, assim, compõem o cortejo fúnebre daquele a quem a obra exalta epiditicamente. E, de modo concomitante, eles estão ligados aos profetas, posicionados sobre colunas que estão dispostas em cada ângulo da base hexagonal.

São personagens, portanto, que participam tanto do anúncio, quanto da catástrofe. Para Lausberg, existem estratégias do discurso que funcionam com vistas ao sobrepujamento da tensão. ${ }^{25}$ Uma delas é a separação das partes do discurso por limites estruturais que podem ser mais nítidos ou mais suaves. Os limites tornam-se mais suaves pela intercalação de uma transitio ou metábase, uma transição entre a situação e o centro do discurso, entre o anúncio e a catástrofe. Lasuberg afirma que, no "decurso de uma narrativa, são muitas vezes necessárias transições, quando as personagens da narração se encontram em lugares diferentes e quando o fio da narração segue as personagens alternadamente". ${ }^{26}$ Assim, as transições atuam como elementos de ligação que efetuam um retorno ao tema, por exemplo, depois de uma digressão.

A presença dos profetas na cena da crucifixão, embora exerça o papel de exórdio, a função anunciativa a que nos referimos, também se constitui em uma digressão, se considerarmos a narrativa tradicional da vida do Cristo. É um

\footnotetext{
${ }^{24}$ Id., ibid., p. 99.

${ }^{25}$ Id., ibid., p. 97.

${ }^{26}$ Id., ibid., p. 100.
} 
afastamento da narrativa do Novo Testamento. Os anjos realizam esta transição. Eles fazem parte das duas cenas, há colunas que os ligam ao passado, posicionando-os entre os profetas, mas suas expressões de dor, de sofrimento diante do testemunho da cena da crucifixão, também podem relacionar-se ao momento posterior. Os anjos carpideiros condensam etapas, como figuras de linguagem, como metonímias, uma vez que pertencem ao tempo do drama sem pertencer exclusivamente a nenhum dos dois momentos representados pelo conjunto. Os oradores do gênero epidítico, como o artista no caso do Poço de Moisés, têm um objetivo presente: louvar o Cristo morto, exaltar sua glória, mas também visam a obter a admiração dos espectadores. Para isso, a cena principal liga-se a argumentos do passado. Os anjos exercem essa função retórica, chamam a atenção do espectador para os momentos dos discursos, unem Velho e Novo Testamento, passado e presente e ainda conclamam, com suas variadas expressões de dor, o olhar dos espectadores, convocando-os afetivamente. As expressões dos anjos fazem um apelo ao espectador quase tão direto quanto as mãos dos profetas que apontam para os textos, anúncio e comoção.

$\mathrm{O}$ aspecto da encomenda é também preponderantemente interessante do ponto de vista da retórica porque situa a obra dentro de um contexto sociocultural particular, em torno da figura do comitente-doador. Para elogiá-lo, o escultor elabora uma cadeia de imagens que têm um aspecto simbólico, mas que também representam um endereçamento específico, com fins políticos e religiosos referentes a uma situação hierárquica. $\mathrm{O}$ caráter espetacular do calvário afirma-se em sua ornamentação. A policromia de Jean Malouel e o douramento de Herman de Colônia não pouparam cores vivas e efeitos brilhantes. De acordo com a descrição de Johan Huizinga,

Nas bases verdes estavam os profetas em mantos dourados, Moisés e Zacarias com seus mantos vermelhos bordaos, azuis por dentro; Davi em azul com estrelas douradas, Jeremias vestindo azul-escuro, Isaías, o mais melancólico de todos, envolto em brocado. Sóis dourados e iniciais preenchiam os lugares abertos. Sem esquecer das armas. Não só em torno da coluna, abaixo dos profetas, brilhavam as impinentes armas das terras do duque, mas nos braços da própria grande cruz, totalmente folheada a ouro, em cujas extremidades, em forma de capitel, foram aplicadas as armas da Borgonha e de Flandres! $!^{27}$

O caráter político da obra, ao ostentar os brasões nas extremidades da cruz, é inquestionável. Mas, além disso, o modelo para a representação de um dos profetas

${ }^{27}$ HUIZINGA, Johan. O outono da Idade Média, op. cit., p. 443-444. 
foi o próprio duque de Borgonha. O elogio do duque vai além da realização de uma obra deste porte que trazia os símbolos da casa de Valois. Seu próprio rosto serviu de inspiração para um dos anunciadores da morte do Cristo, Daniel [fig. 5, pág. 272]. A inclusão do comitente na própria obra reforça o caráter epidítico do discurso figurativo. O impacto dessa conjunção de elogios, a força políticoteológica do calvário foi tão grande que culminou, em 1418, com a concessão de uma indulgência pelo papa a quem quer que fosse visitar o Poço de Moisés com "objetivos piedosos".

Por fim, a obra realiza outro elogio: o do próprio artista que a concebeu sob encomenda do duque de Borgonha. O calvário foi o primeiro trabalho realizado pelo artista sob sua total responsabilidade após ter passado a viver como servidor da corte na Borgonha e, portanto, uma importante "propaganda" de sua competência e um atestado definitivo de seu merecimento. Somente após o final da obra do calvário de Champmol, em 1404, foi entregue à responsabilidade do artista o planejamento e execução de outra de suas grandes obras: o túmulo de Philipe o Bravo, com seus 40 carpideiros. Após a execução do calvário, portanto, Sluter passou a ser o principal artista a serviço do príncipe em Dijon. Da recepção do Poço de Moisés dependeu uma importante mudança de seu status na Borgonha. Suas estratégias retóricas, as escolhas realizadas e, em última instância, a tomada de posição realizada através da obra tiveram efeitos muito práticos e imediatos na vida do artista.

Esse dado reforça a natureza epidítica do conjunto escultórico. Perelman nos diz que este tipo de discurso visa a "reforçar uma disposição para a ação ao aumentar os valores que ele exalta". ${ }^{28}$ Para Perelman, a reputação do orador não é o objetivo principal do discurso, mas uma consequência previsível e costumeiramente prevista.

Assim, o discurso epidítico, em lugar de pretender estabelecer de uma vez por todas o vínculo entre verdades especulativas, se propõe, através de certas estratégias, como o uso de metáforas e de uma lógica de disposição, como tentei demonstrar aqui, a aumentar intensidade da adesão a certos valores. Sobre os valores em favor dos quais o discurso epidítico no Poço de Moisés argumenta não necessariamente pairariam dúvidas, se considerados isoladamente. No entanto, a obra como um todo é um elogio cuja intensidade busca reforçar tais valores diante de um possível conflito, ainda que imaginário. E evitar que outros se sobreponham a eles diante de possíveis conflitos futuros. $\mathrm{O}$ artista criou a obra em comunhão

\footnotetext{
${ }^{28}$ PERELMAN, Chaim; OLBRECHTS-TYTECA, Lucie. Tratado da argumentação. A nova retó-
} rica. Trad. Maria Ermantina de Almeida Prado Galvão. São Paulo: Martins Fontes, 2002, p. 56. 
com valores compartilhados e reconhecidos pelos espectadores, valendo-se de procedimentos retóricos que amplificam e intensificam esses valores, ao tempo em que geram a comoção típica do espetáculo.

$$
* * *
$$

Conscientes dos elogios que a obra realiza, é importante retomar a análise clássica do Poço de Moisés realizada por Huizinga. Ao leitor contemporâneo, cabe questionar se os elementos considerados excessivos pelo autor não se constituem partes fundamentais de um discurso epidítico, posicionados de modo intencional com o objetivo de alcançar uma resposta que estrategicamente convinha ao contexto de realização do conjunto. A análise de Huizinga, que denomina aspectos da obra como excessivos ou bizarros, evidencia a decadência da retórica como pensamento hegemônico na primeira metade do século XX.

$\mathrm{Na}$ França deste período, é bastante forte uma tendência a desqualificar a cultura retórica e de afastá-la das análises teóricas de arte e literatura. Em L'art de la prose, Gustave Lanson, que havia publicado, em 1880, Conseils sur l'art d'ecrire, em que enfatizava fortemente a importância dos estudos retóricos, não menciona uma única vez a palavra "retórica". Como bem observa Marc Fumaroll:

Il ne pas prononce jamais le mot 'rhétorique', mais ce qu'il appelle "art de la prose" n'en pás très éloigné: "les genres et les styles ont des lois et des règles. (...) Lois et règles ont eu toujours pour fonction d'indiquer les moyens les plus sûrs d'executer le travail littéraire, de façon que chaque effort ait son maximum de rendement. Il y a donc un art de la prose". ${ }^{29}$

A crítica de Lanson assinala para a existência de qualidades gerais do discurso e vai além. Para ele, existe uma prose d'art que ele pretende ensinar, como sublinha Fumaroll, virando as costas à retórica, ou nas palavras de Lanson:

Ce n'est pas que je pretende donner la recette de la prose artistique: la prétension serait puérile et vaine. Ceux qui se flattent de l'enseigner sont des charlatans ou des naïfs. ${ }^{30}$

Essa perspectiva lansoniana dos artifícios retóricos e daqueles que os empregam consciente e explicitamente culminou em sua obra com a ideia de que o trabalho do estilo não se fazia através de regras, mas do gênio criativo dos grandes

29 FUMAROLLI, Marc. Histoire de la rhétorique dans l'Europe moderne. 1450-1950. Paris: Presses Universitaires de France, 1999, p. 1241.

${ }^{30}$ LANSON, 1909, p. 19. Apud FUMAROLLI, op. cit., p. 1242 
artistas. Assim, portanto, não caberia aos estudiosos a compreensão da linguagem segundo uma lógica de intencionalidades. Para ele, como assinala Fumaroll: ${ }^{31}$

Il ne faut pas nous laisser croire, à nous qui sommes de bons bourgeois, professeurs, gens du monde, industriels, financiers, journalistes, etc., que ces procedés artistiques de création d'um style soient à notre usage (...). Pour nous, qui sommes le public, contentons-nous de jouir des belles proses, et d'affiner, de multiplier par l'étude et l'observations de nos jouissances.

A propensão a desqualificar a análise dos procedimentos artísticos segundo os métodos retóricos é, portanto, não só vigente, como crescente e difundida na Europa ao tempo em que Huizinga escreveu sua análise do Poço de Moisés. Tratar como excessos e extravagâncias os recursos utilizados pelo artista na própria lógica do pathos do conjunto escultórico demonstra uma tendência dos estudiosos da primeira metade do século XX. A presença considerável da retórica, sobretudo da Idade Média à Renascença, não é tratada nos estudos de então. Segundo Fumaroll, todo um campo das pesquisas retóricas começa a ser negligenciado na França nesse momento, o que culmina, segundo o autor, com o fim da hegemonia do studium rhetoricum que organizou os currículos por mais de dois mil anos, como uma aprendizagem da vida pela linguagem. ${ }^{32}$

O que propusemos brevemente nesse artigo é que as análises contemporâneas do Poço de Moisés levem em consideração o contexto de produção dos estudos clássicos a respeito da obra, especialmente daqueles datados do fim do século XIX e início do século XX, como o de Huizinga, escrito no auge da decadência dos estudos retóricos nas pesquisas formais. As novas análises do conjunto escultórico devem questionar-se acerca da terminologia empregada para descrever o Poço e do método analítico que prescinde de observar uma certa estruturação da linguagem da obra consoante com a preponderância do emprego de recursos retóricos na Idade Média, quando foi erigida.

Os exemplos de análise que trouxemos aqui retomam a terminologia da retórica clássica, tendo em vista a proposta de autores como Richard Lanham, para quem o homo rethoricus opõe-se ao homo seriosus. ${ }^{33} \mathrm{O}$ homem retórico é um ator, sua realidade é pública e dramática. Ele muda de orientação, reconhece os paradigmas, explora suas fontes e possibilidades.

${ }^{31}$ Id., p. 1.243 .

${ }^{32}$ Id., ibid.

${ }^{33}$ FISH, Stanley. Doing what comes naturally. Change, rhetoric and the practice of theory in literary and legal studies. Durham: Duke University Press, 1989, p. 482. 
Stanley Fish observa que, entre sofistas e platônicos, por exemplo, respectivamente homens retóricos e homens sérios, o que há, sobretudo, é uma diferença de visões de mundo. À acusação de que a retórica existe nos reinos do provável, do contingente e da mentira, os sofistas respondiam que a verdade mesma é um assunto contingente que assume diferentes formatos à luz das necessidades e convicções específicas de cada tempo e lugar. Para eles, a verdade era individual e temporária, não contínua e universal, uma vez que a verdade para qualquer homem era aquilo de que ele poderia ser persuadido. ${ }^{34}$ Realidade, para o homem retórico, não é algo a ser descoberto, mas manipulado, é o que se aceita, o que é útil, é algo fluido. Cremos, por conseguinte, que a obra de Sluter é trabalho de um artista retórico daqueles que não abdicam do ornamento, do adorno, da disciplina da arte como discurso. Ele está entre aqueles cujo denominador comum da vida são suas circunstâncias, fundamento de suas escolhas, em lugar de apenas um padrão objetivo ou de uma norma contumaz.

Recebido: 20/05/2011 - Aprovado: 20/09/2011.

${ }^{34}$ Id., ibid., p. 481. 